\title{
Effects of Repeated Frying on Physical Properties of Cooking Oil obtained from Wurukum Market in Makurdi Metropolis, Benue State, Nigeria.
}

\author{
T. Daniel ${ }^{\mathrm{a}, 1, *}$, F. Eriba-Idoko ${ }^{\text {a }}$, J. O. Tsor ${ }^{\mathrm{a}}$, S. T. Kungur ${ }^{1}$, E. O. Enokela ${ }^{\mathrm{a}}$, F. Gbaorun ${ }^{\mathrm{a}}$, E. C. \\ $\mathrm{Hemba}^{\mathrm{c}}$, A. A. McAsule ${ }^{1}$, N. S. Akiiga ${ }^{1}$, P. O. Ushie $^{1}$ \\ ${ }^{a}$ Department of Physics, Benue State University, Makurdi \\ ${ }^{b}$ Department of Physics, College of Education, Katsina-Ala, Benue State \\ ${ }^{c}$ Department of Physics, Federal College of Education, Pankshin, Plateau State \\ ${ }^{d}$ Department of Physics, Federal University of Agriculture, Makurdi, Benue State \\ ${ }^{e}$ Department of Physics, Faculty of Physical Sciences, Cross River University of Technology, Calabar
}

\begin{abstract}
The viscosity, density and specific gravity of different brands of cooking oil samples locally sourced for in Makurdi have been measured with respect to change in temperature. The viscosity of the different brands of cooking oil was measured with the instrumentality of Brookfield Viscometer. The density and specific gravity were evaluated using the mass of the sampled oil obtained with the help of the density bottle. The result showed a pattern of rapid decrease in viscosity with increase in temperature for the oil samples, while density decrease is observed to be almost linear with increase in temperature for all samples. Amongst the sampled cooking oils, palm kernel showed the least viscosity of 8.6 Pascal-second when measured at $45.20^{\circ} \mathrm{C}$. This illustrates that palm kernel oil has a relatively low viscous nature at $45.200 \mathrm{C}$ as compared to other samples used in this work.
\end{abstract}

DOI:10.46481/jnsps.2021.298

Keywords: Cooking Oil, Frying, Brookfield Viscometer, Viscosity and Temperature

Article History :

Received: 30 June 2021

Received in revised form: 04 September 2021

Accepted for publication: 14 September 2021

Published: 29 November 2021

(C)2021 Journal of the Nigerian Society of Physical Sciences. All rights reserved. Communicated by: Edward Anand Emile

\section{Introduction}

Cooking oils are vital ingredients for preparing most of everyday food in many parts of the world and in particular, they are known to be rich sources of beneficial dietary nutrients that contribute to human health [1-2]. Palm trees, Olive plants,

${ }^{*}$ Corresponding author tel. no: $+234(0) 8167598988$

Email address: terver.daniel@yahoo.co.uk, tdaniel@bsum.edu.ng (P. O. Ushie) cocoa-nut trees, groundnut and soybean plants are few examples of plants whose seeds and fruits can be processed in order to extract various kinds of cooking oils that are mostly consumed on daily basis in this part of the world. These plants are widely cultivated in different parts of the country of which Benue State being the Food Basket of the Nation [3-4] produces these on a high commercial scale [3]. The production of cooking oils can be done by pressing or crushing the plant seeds or fruits before extracting the oil. These processes are either local or modernized depending on the equipment used and their 
availability. Some are further refined by application of heat to remove unwanted component(s), while others are marketed without further refining. Out of the total production of cooking oils, $75 \%$ is used for direct cooking of day-to-day meals both for frying and non-fried meals. The remaining $25 \%$ is being used in industries as local sources for production of other industrial commodities such as biscuits, detergents etc. [5-6].

Food frying involves immersing the food to be fried (such as sliced pieces of yam, plantain, potatoes, fish, beans cake etc.) completely in a bath of hot oil under the supply of heat (though not necessarily with a defined quantity of heat) for a particular period of time until the immersed food turns yellowish in nature. The hot cooking oil usually processes the food during the frying process by dehydrating the food moisture content leading to both chemical and physical changes in the food thereby reducing its mass and making it porous and crispy. Frying usually affects the characteristics taste, texture and the color of the food [7]. Food frying can be used for food preservation and food processing. The quantity of heat supplied affects both the chemical and the physical properties of the cooking oil. For instance, extreme supply of temperature to cooking oil is a factor that lead to increase in acid value in oils [8]. High acid value indicates high free fatty acid, which in turn, causes oil to become rancid [9] and ingestion of acids especially trans- fatty acids appears to increase blood cholesterol, in particular low-density lipoproteins to high-density [6].

High levels of low lipoproteins in the blood have been linked to arteriosclerosis, a disease of the heart that can cause stroke, heart attack [10-11] and other serious health problems as a result of cholesterol deposits that form plaques on the inner surfaces of the arteries obstructing blood flow [8]. This causes a disease called arteriosclerosis. Due to increasing awareness on the health implications of bad cholesterols in diet, most people now prefer to purchase vegetable oils with low density lipoproteins [12]. It has been demonstrated that free fatty acids, change of color, smoke point, iodine values, total polar materials, interfacial tension, density, cloud point, pour point, flash point, boiling range, freezing point, refractive index, foaming properties and viscosity are indicators used to determine the quality of cooking oils [13-16]. This is to say that: frying of food may bring out the aroma, enhance the flavor and texture combination which is very desirable for consumption, making fried foods one of the most popular food products [17]. Conversely, when cooking oils are stored for a long time, excessive recycling or exposed to excessive heat, oil degradation occurs [1819], and by-products are produced [20]. Elevated temperatures, especially temperature above the smoking point of the oil, will cause significant change in its quality due to the chemical and physical reactions [21]. Some by-products of oil degradation have adverse effects on human health [7, 20, 22].

Previous studies have revealed the effect and health risks associated with eating fried food [7-8, 23-25]. Also, other several researchers have focused on effect of temperature on physical properties of cooking oil at high temperature up to and above their smoking points $[9-10,17,24,26]$, without taking into account however, how repeated use of the same cooking oil for deep frying affects these properties. Our present study focused on the effect of repeated frying on some physical properties of cooking oil purchased from local markets in Makurdi, Benue state. Uniquely in this work, we maintain a minimal temperature (temperature well below the smoking point temperature of each cooking oil) $[10,17,22]$ in the frying process, using the same cooking oil repeatedly for frying of yam and potatoes for several days while keeping track of the changes in some of the physical properties of each cooking oil on a daily basis. Additionally, the motivation for this work was further honed by the limited availability of data on the physical properties of cooking oils in North Central, Nigeria. Also owing to the fact that Benue State is classified as the Food Basket of the Nation in Nigeria, information on the physical properties of oils with respect to changes in temperature will further call for high quality breeds of seedlings for farmers that could mitigate these short changes in the long run.

\section{Physical Properties of Cooking Oil}

The physical properties of cooking oils are free fatty acids, change of color, smoke point, iodine values, total polar materials, interfacial tension, density, cloud point, pour point, flash point, boiling range, freezing point, refractive index, foaming properties and viscosity [13-16]. However, the physical properties of cooking oil measured in this work included the viscosity, density and specific gravity based on availability of instrumentation and other requirements.

\subsection{Viscosity}

Viscosity is an important physical property of a fluid system including cooking oil being a function of shear rate, temperature, pressure, moisture content, concentration and flow rate. It differs from fluid to fluid because they are made of different particles with different forces of attraction between them. Examples of these fluids can be engine oil, honey, cooking oils and water. It is important to note that the viscous forces are called into play as soon as fluid flow starts. If the external force causing the flow are constant, the rate of flow becomes constant and a steady state is attained with the resisting viscous forces equal to the applied force. The viscous force stops the flow when the applied force is removed. Viscosity can be expressed in two distinct forms known as dynamic viscosity $(\eta)$ and the kinematic viscosity $(v)$. They are mathematically expressed respectively as according to [27] as,

$$
\eta_{o i l}=\frac{\tau}{\gamma} \& v_{o i l}=\frac{\eta_{o i l}}{\rho_{o i l}}
$$

where $\tau$ is the shear stress, $\gamma$ is the shear rate and $\rho_{o} i l$ is the oil density. The viscosities of the oil samples used in this work are measured using the Brookfield viscometer.

\subsection{Density}

The density of cooking oil influences its absorption as it affects the drainage rate after frying and also the mass transfer rate during the cooling stage of frying. The density of a substance is the property that describes the amount of matter that is 
packed in a small space. It is measured throughout industry to gain insight into the purity, concentration, quality and behavior of substance. The density of cooking oil is expressed mathematically as $[13,27]$

$$
\rho_{o} i l=\frac{m_{\text {oil }}}{v_{\text {oil }}}
$$

where $\rho_{o} i l$ is the oil density in $\mathrm{g} / \mathrm{cm}^{3} . m_{o} i l$ is the mass of the oil in gram and $v_{o} i l$ is the oils volume in $\mathrm{cm}^{3}$.

\subsubsection{Specific Gravity}

Specific gravity is an important parameter in cooking oil because of its correlation with cetane number, heating value and storage time. The greater the specific gravity of oil, the higher its energy content. The specific gravity of cooking oil was obtained using the equation 3 [13];

$$
\text { Specific Gravity }=\frac{\rho_{\text {oil }+ \text { bottle }}-\rho_{b} \text { ottle }}{\rho_{\text {water }+ \text { bottle }}-\rho_{\text {bottle }}}=\frac{\rho_{\text {oil }}}{\rho_{\text {water }}}
$$

\section{Materials and Method}

\subsection{Geology of Area of Study}

Makurdi metropolis doubles as the state capital of Benue State in Nigeria and also serves as the headquarters of the Makurdi Local Government Area with the geographical coordinates $7.73^{\circ}$ $\mathrm{N}$ and $8.53^{\circ} \mathrm{E}$ [28-29]. In 2016, Makurdi and its environs had an estimated population of about 365,000 persons [30]. The town is divided by the River Benue into the North and South Banks, which are connected by two bridges of about $1 \mathrm{~km}$ long each. Due to the fact that Makurdi is located in the valley of River Benue [29, 31], it experiences a temperature fluctuation of between $21-37^{\circ} \mathrm{C}$ in the year [30,32]. Within the Makurdi metropolis, there are five major markets namely: Wurukum, Wadata, Makurdi Modern, International, North Bank and the High-level Markets which are the major trade centers for soybeans, groundnut, shea nut, millet, sorghum, rice, maize, yams, tomatoes, water melon, and other seedlings at various quantities etc. The markets and other features of Makurdi town are as shown in Figure 1.

Benue state is predominantly an agricultural area specializing in both cash and subsistence crops [30]. The vegetation is mainly savanna [32] with the southern part of the state characterized by forests, thus, fertile for growing palm trees, consequently, ranking Benue State among producers of palm oil in Nigeria. However, the oil samples used in this work were purchased from Wurukum market due to the proximity to the University Research Laboratory.

\subsection{Sample Collection}

The cooking oil samples used in this work include groundnut oil, palm oil, coconut oil, olive oil, palm kernel oil and soybeans oil. They were purchased from Wurukum market a major market in Makurdi metropolis that is situated few meters away from the Benue State University, Nigeria. While

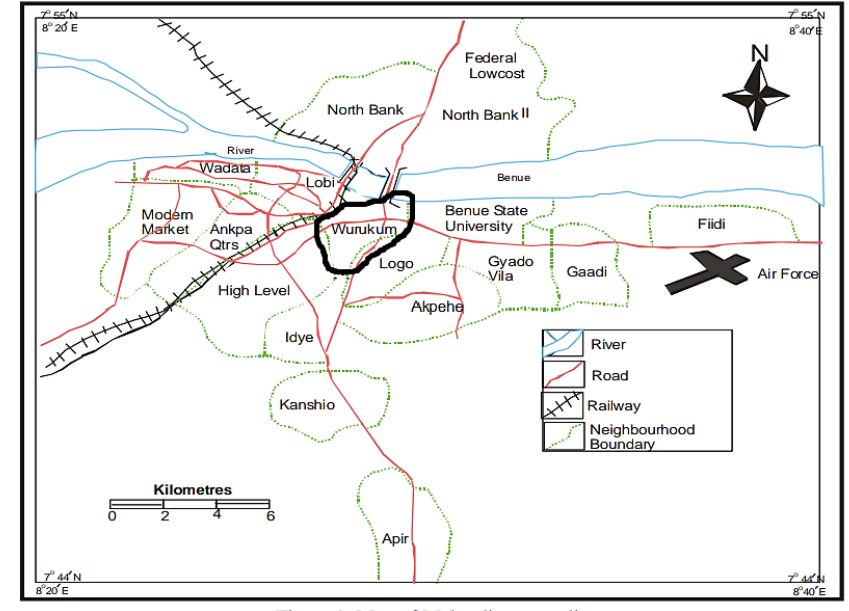

Figure 1. Map of Makurdi Metropolis, Ministry of Lands and Survey, Benue State showing Wurukum Market [33].

the soybeans oil was purchased at the Seraph company along Makurdi - Gboko Road, Makurdi, Benue state. All the oil samples were moved to the Research Laboratory in the Department of Physics, Benue University Makurdi, Nigeria in plastic bottles, where they were properly labelled and stored at a room temperature for two days before experiment.

\subsection{Measurement of Viscosity}

The viscosities of the different brands of cooking oils were measured using the Brookfield Viscometer. Brookfield viscometers employs the well-known principle of rotational viscometry; which measures viscosity by sensing the torque required to rotate a spindle at constant speed while immersed in the sample fluid. The torque is proportional to the viscous drag on the immersed spindle, and thus to the viscosity of the fluid. The continuous rotation of the spindle allows uninterrupted measurements to be made over long periods of time depending on the fluid properties. The viscosities of each of the six (6) samples of the cooking oil (at room temperature) without frying, were measured using the Brookfield viscometer at room temperature. The measurements for each oil sample were performed and recorded as shown in Table 1.

5. $00 \mathrm{~mL}$ of groundnut oil was poured in a frying pan and heated up to a temperature of $120^{\circ} \mathrm{C}$. A tuber of yam and six (6) tubers of potatoes were sliced, poured into the frying oil and allowed to fry well enough for human consumption. The frying process for all the six (6) brands of oil was carried out almost concurrently. During the frying process, the temperature of the frying oil was maintained at a temperature below the smoking point of the oil. At the end of each frying, the oil was allowed to cool before taking the viscosity measurement at a constant temperature every day for five (5) consecutive days. Viscosity for each oil sample was measured and plotted as shown in Figure 2. Again, while varying the temperature of each oil sample each consecutive day for five days, their viscosity was measured and recorded as shown in Table 2 . The same variety of yam and 


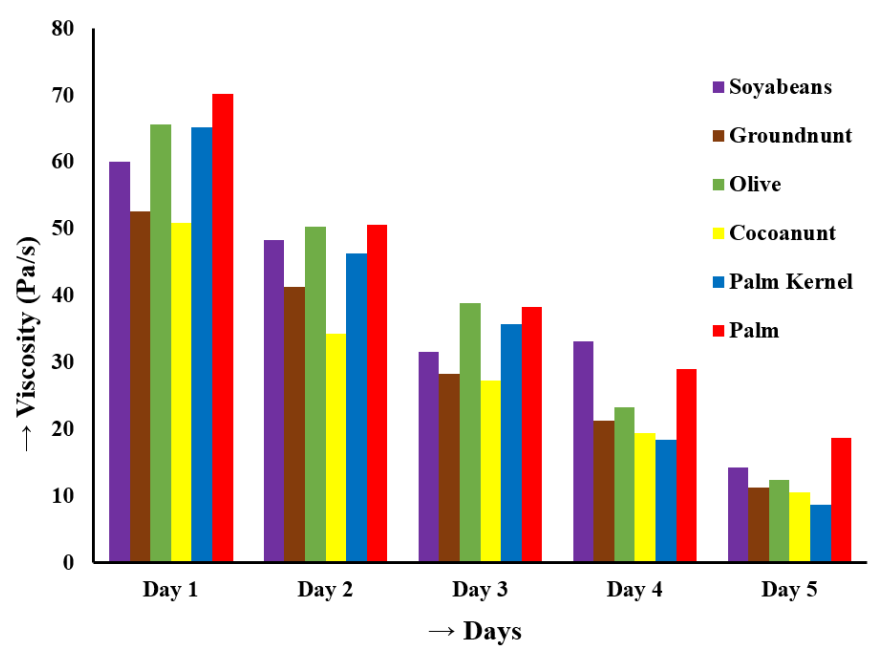

Figure 2. Viscous change measured at constant temperature per day after recycled usage of cooking oils for frying of yams and potatoes

potatoes with the same cooking oils were repeatedly used in all the five days in the frying process.

\subsection{Determination of Oil Density}

To obtain the densities of the oil samples, we use the density bottle to measure the mass and volume of each oil sample before evaluating their corresponding densities using equation 2. To do that, we first of all measure the mass of the dry and empty density bottle using the electronic weighing balance and its volume was evaluated using equation 4 as expressed

$$
\text { Volume }=\frac{m_{\text {water }}-m_{\text {bottle }}}{\rho_{\text {water }}-\rho_{\text {air }}}
$$

The result of equation 4 is substituted for the volume of oil in equation 2 and the results for the densities of the cooking oils are recorded as shown in Table 3.

\subsection{Experimental Results}

In this section, the results that were gotten in the various investigations of the physical properties considered in this study are duly presented and discussed as shown below

\section{Discussions}

\subsection{Viscosity}

The results for the viscosity of soybean oil, groundnut oil, olive oil, coconut oil, palm kernel oil and palm oil measured at room temperature without frying are presented in Table 1 and plotted as in Figure 3. While Table 2 presents the results of viscosity of the sampled cooking oils measured each day after frying of sliced yams and potatoes repetitively for five consecutive days at varying temperature. From Table 1, the viscosities ranged from $61 \mathrm{mPa}$.s to $111 \mathrm{mPa}$.s with palm oil having the highest viscosity of $110.96 \mathrm{mPa} . \mathrm{s}$ and the lowest value is reported in palm kernel oil as $61.12 \mathrm{mPa}$.s. This is clearly depicted in Figure 3. The result for soybeans at $24^{\circ} \mathrm{C}$. is 96.82

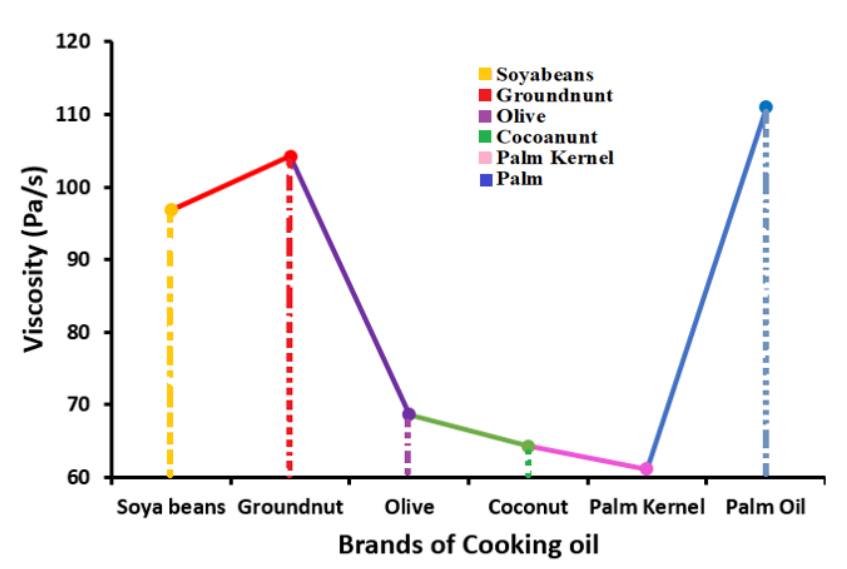

Figure 3. Viscosity of cooking oil samples without frying and measured at room temperature

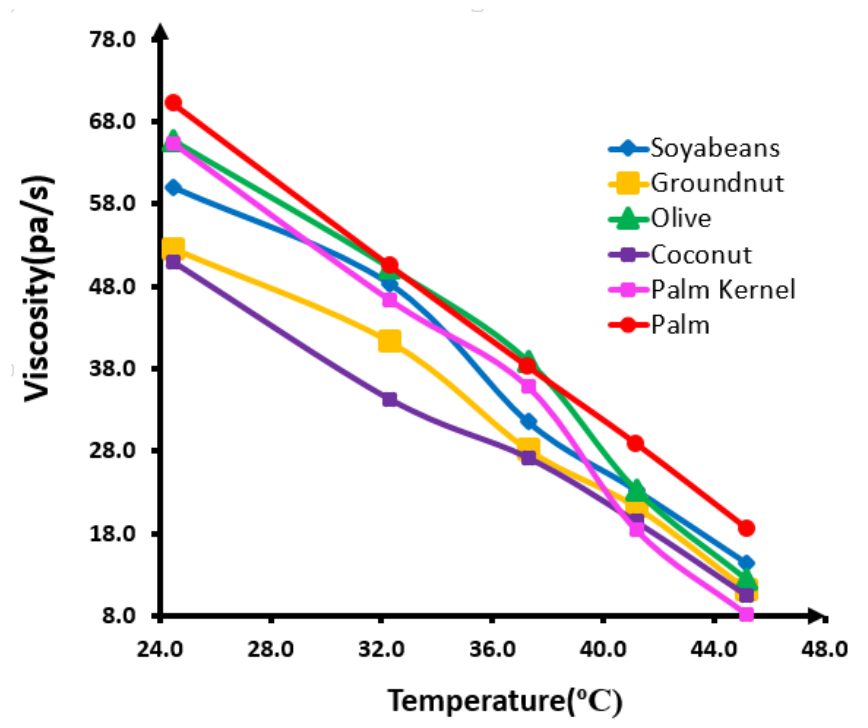

Figure 4. Viscosity versus temperature of cooking oil samples after repeated frying of yams and potatoes for five successive days 
Table 1. Viscosity $\left(\mathrm{Pas}^{-1}\right)$ of cooking oil sample without (that is, at room temperature) frying.

\begin{tabular}{ccc}
\hline Oil sample & Viscosity $\left(\mathrm{Pas}^{-1}\right)$ & Temperature $\left({ }^{0} \mathrm{C}\right)$ \\
\hline Soya beans & 96.82 & 23.90 \\
Groundnut & 104.27 & 23.10 \\
Olive & 68.62 & 22.70 \\
Coconut & 64.26 & 24.10 \\
Palm Kernel & 61.12 & 23.60 \\
Palm Oil & 110.96 & 23.20 \\
\hline
\end{tabular}

Table 2. Viscosity $\left(\mathrm{Pas}^{-1}\right)$ of cooking oils used for frying yams and potatoes for five consecutive days.

\begin{tabular}{|l|l|l|l|l|l|l|l|}
\hline & \multicolumn{7}{|l|}{ Viscosities of oil Samples $\left(\mathrm{pas}^{-1}\right)$} \\
\hline Days & $\begin{array}{l}\text { Temperature } \\
\left({ }^{0} \mathrm{C}\right)\end{array}$ & $\begin{array}{l}\text { Soya } \\
\text { beans }\end{array}$ & Groundnut & Olive & Coconut & $\begin{array}{l}\text { Palm Ker- } \\
\text { nel }\end{array}$ & Palm Oil \\
\hline Day 1 & 24.50 & 60.00 & 52.61 & 65.67 & 50.91 & 65.27 & 70.21 \\
\hline Day 2 & 32.30 & 48.30 & 41.34 & 50.26 & 34.32 & 46.32 & 50.57 \\
\hline Day 3 & 37.30 & 31.52 & 28.21 & 38.92 & 27.21 & 35.78 & 38.26 \\
\hline Day 4 & 41.20 & 33.20 & 21.25 & 23.24 & 19.46 & 18.45 & 28.92 \\
\hline Day 5 & 45.20 & 14.31 & 11.21 & 12.36 & 10.52 & 8.6 & 18.61 \\
\hline
\end{tabular}

Table 3. Densities, $\rho\left(\mathrm{g} / \mathrm{cm}^{3}\right)$, of the cooking oil at different temperature obtained after repeatedly frying yams and potatoes for five days.

\begin{tabular}{|l|l|l|l|l|l|l|}
\hline \multicolumn{7}{|l|}{ Density of Oil Samples $\left(\mathrm{g} / \mathrm{cm}^{3}\right)$} \\
\hline $\begin{array}{l}\text { Temperature } \\
\left({ }^{0} \mathrm{C}\right)\end{array}$ & $\begin{array}{l}\text { Soya } \\
\text { beans }\end{array}$ & Groundnut & Olive & Coconut & Palm Kernel & Palm Oil \\
\hline 20.0 & 0.900 & 0.900 & 0.910 & 0.870 & 0.880 & 0.920 \\
\hline 40.0 & 0.890 & 0.860 & 0.880 & 0.860 & 0.860 & 0.890 \\
\hline 60.0 & 0.880 & 0.850 & 0.860 & 0.860 & 0.850 & 0.870 \\
\hline 80.0 & 0.840 & 0.830 & 0.840 & 0.850 & 0.840 & 0.850 \\
\hline 100.0 & 0.810 & 0.820 & 0.840 & 0.820 & 0.830 & 0.820 \\
\hline
\end{tabular}

Table 4. Specific gravities of the cooking oil at different temperature obtained after repeatedly frying yams and potatoes for five days consecutively.

\begin{tabular}{|l|l|l|l|l|l|l|}
\hline & \multicolumn{6}{|l|}{ Specific Gravity of Oil Samples } \\
\hline Temperature $\left({ }^{0} \mathrm{C}\right)$ & $\begin{array}{l}\text { Soya } \\
\text { beans }\end{array}$ & Groundnut & Olive & Coconut & Palm Kernel & Palm Oil \\
\hline 20.0 & 0.903 & 0.903 & 0.913 & 0.873 & 0.883 & 0.883 \\
\hline 40.0 & 0.893 & 0.832 & 0.883 & 0.863 & 0.853 & 0.873 \\
\hline 60.0 & 0.883 & 0.842 & 0.863 & 0.853 & 0.842 & 0.873 \\
\hline 80.0 & 0.842 & 0.853 & 0.842 & 0.863 & 0.832 & 0.893 \\
\hline 100.0 & 0.812 & 0.822 & 0.842 & 0.822 & 0.832 & 0.822 \\
\hline
\end{tabular}




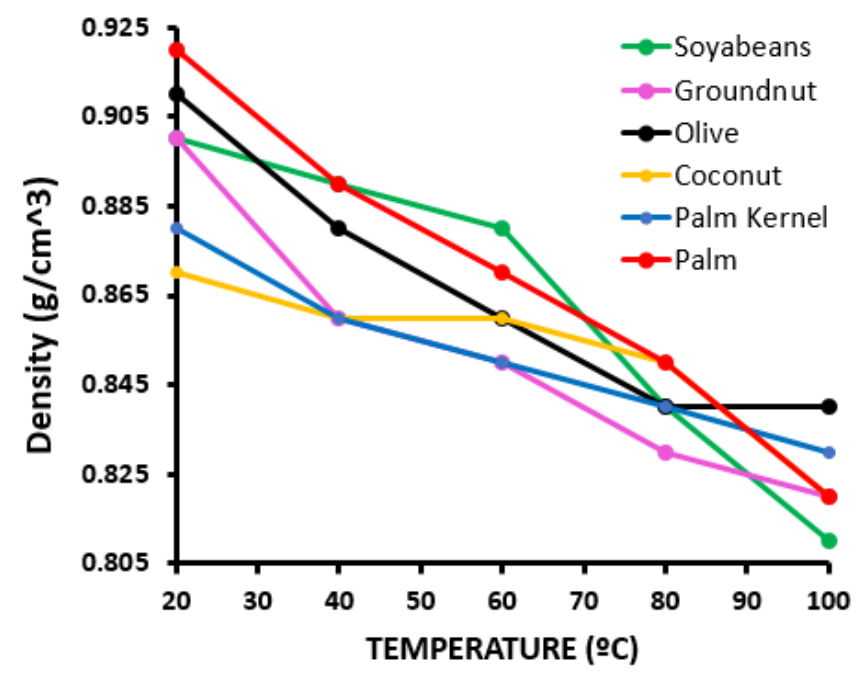

Figure 5. Density of different brands of cooking oil against temperature obtained after repeated frying of yams and potatoes for five successive days.

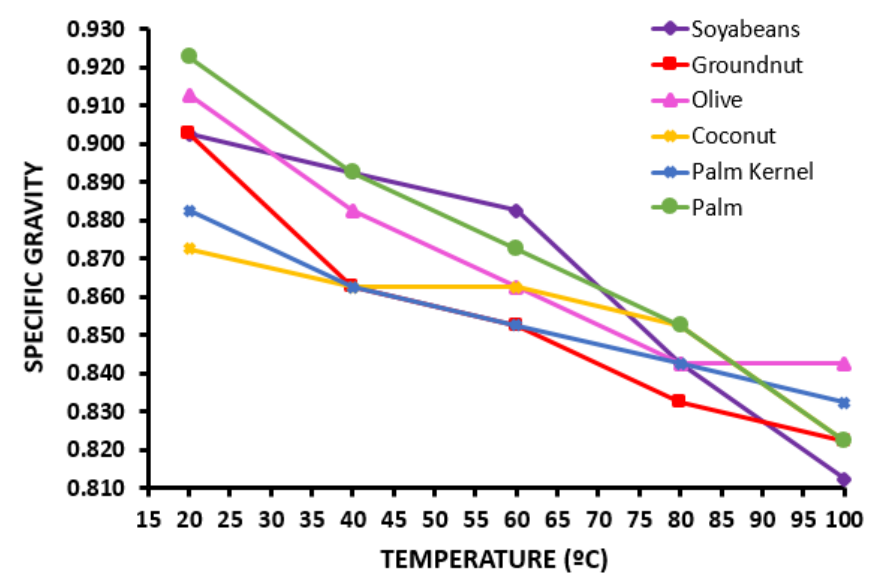

Figure 6. Specific gravity of different samples of cooking against temperature for five successive days obtained after repeated frying of yams and potatoes
mPa.s. This value is far higher when compared to [26] and [34] which are $60 \mathrm{mPa}$.s at $20^{\circ} \mathrm{C}$ and $57.1 \mathrm{mPa}$.s at $22^{\circ} \mathrm{C}$ respectively. While the result of [34] is a theoretical prediction that was modelled mathematically using the Andrade equation, [2]6 is contrarily an experimental result measured with the use of MCR301 Rheometer - a device that employ the principle of rotational viscometery which is similar to the Brookfield viscometer used in this work. However, the large disparity of about $36.8 \mathrm{mPa}$.s in this result and [26] is not only due to the temperature difference of $4^{\circ} \mathrm{C}$ but largely because, the viscometers were operated at different shear rate, which corresponds to the rate of spindle rotation in oil solution per minute (RPM). The Brookfield viscometer was operated at a shear rate of 60 RPM while the rheometer as in [26] was operated at 750 RPM. Whereas, higher shear rate corresponds to higher spindle speed in oil solution [35] and thus, lower viscosity measurement as observed in this result. The results in Figure 2 shows that, viscosity decrease as the number of days of recycled use of the same oil to fry sliced yams and potatoes increases continually for five successive days. The viscosity of palm oil for instance decreased from $70.21 \mathrm{mPa}$.s in day 1 to $50.57 \mathrm{mPa}$.s in day 2 to $38.26 \mathrm{mPa}$.s in day 3 to $28.92 \mathrm{mPa} . \mathrm{s}$ in day 4 to $18.61 \mathrm{mPa}$.s in day 5 . Since the viscosity of a solution is dependent on the intermolecular forces and the interaction within its molecules, the continuous decrease in viscosity after each repeated frying is because, continuous application of heat to the oil each day for five days results in continuous breakdown of the oil layers. This breakdown weakens the intermolecular forces and the bond energies of oils molecules that restrict molecular rotational motion of the viscometer spindle within the oil solution, and therefore, lower viscosity is recorded as the number of days of repeated frying increase. The results plotted in Figure 4 reveal a steady linear decrease in viscosity as the temperature of the cooking oils increases. A similar trend was observed for olive oil, palm oil and soybean in [27], and in coconut oil and soybean as in [14]. We observed that palm oil has the highest viscosity for all the five-oil follow by olive oil and groundnut oil while the oil with least viscosity is palm kernel.

\subsection{Density and Specific gravity}

The density and specific gravity of cooking oil varied significantly with change in temperature as shown in Tables 3 and 4 respectively. A general trend of decrease in these two physical properties of cooking oils were observed in Figures 5 and 6 as temperature increases from $20^{\circ} \mathrm{C}$ to $100^{\circ} \mathrm{C}$. This decrease in the density of the cooking oil with increased temperature was also observed [13, 27, 34] and same trend being applicable for specific gravity $[10,13,36]$. The decrease in density and specific gravity of the oils due to increase in temperature lead to breakdown of the oils structure. This causes the mass of the oils to reduce as frying progresses even though the volume or the quantity of this oil that was used in frying at the initial place may still be the same 


\section{Conclusion}

This work has shown that the thermal (heat) properties of different oils determine their superiority over others when subjected to the same amount of weather conditions. Based on the results obtained from research, temperature had a significant effect on all three physical properties (viscosity, specific gravity and density) of oils measured. Oil type was shown to have a significant effect on viscosity, density and specific gravity. A general trend for all the properties decreased with increased temperature as can be seen from Figures 4 to 6 . The effect of temperature on the viscosity for all the vegetable oils show a linear relationship for all temperatures used in this work. Although [34] reported non-linear decrease in viscosity at very high temperature above $100^{\circ} \mathrm{C}$. This is an indication that temperature had significant effect on viscosity of vegetable oils. Oil that has been used repeatedly for so long at high temperatures are not advisable for human consumption because its qualities such as the viscosity, density, specific gravity etc have been reduced. Density decreased linearly with increased temperature whereas specific gravity decreases almost linearly in comparison with the other physical properties measured in this work.

\section{Acknowledgment}

We wish to appreciate the Head of the Department of Physics, Professor Frederick Gbaorun for allowing this experiment to be conducted in the laboratory of the Department. The authors also wished to thank all the Laboratory staff of the Department of Physics for their assistance during measurement and data analysis as well as interpretations and discussions of the results obtained. Lastly, the authors are grateful to God for a good life that all of them are enjoying and the wisdom to conduct this research.

\section{References}

[1] N. Morgan, "Food consumption: world vegetable oil consumption expands and diversifies", Food Rev. (1993) 26.

[2] E. Ike, "The study of viscosity-temperature dependence and activation energy for palm oil and soybean oil", Glob. J. Pure Appl. Sci. 25 (2019) 209. Available at https://doi.org/https://dx.doi.org/10.4314/gjpas.v25i2.11.

[3] S.K. Upev, L. Haruna, D.Y. Giroh, "Analysis of resources use efficiency among soybean (glycine max) farmers in Gboko Local Government Area of Benue State", Nigeria., Glob. J. Agric. Sci. 15 (2016) 57.

[4] List of Nigerian States' name. Retrieved on June 4, 2021 from Wikipedia.

[5] USDA FAS, Global Market Analysis: Oilseeds, World Market and Trade, (2021) 1 .

[6] P. Shankar, S. Ahuja, A. Tracchio, "Coconut oil: a review", Agro Food Ind. Hi Tech. 24 (2013) 62. Available at https://www.researchgate.net/publication/264157941.

[7] N.K. Andrikopoulos, G. Boskou, G.V.Z. Dedoussis, A. Chiou, V.A. Tzamtzis, and A. Papathanasiou, "Peer review quality assessment of frying oils and fats from 63 restaurants in Athens, Greece", Food Serv. Technol. 3 (2003) 4. Available at https://doi.org/10.1046/j.14715740.2003.00064.x.

[8] V. Sodano, R. Riverso, F. Scafuto, "Investigating the intention to reduce palm oil consumption", Qual. - Access to Success. 19 (2019) 500. Available at https://www.researchgate.net/publication/323759111.

[9] H.A. Mudawi, M.S.M. Elhassan, A.M.E. Sulieman, "effect of frying process on physicochemical characteristics of corn and sunflower oils", Food Public Heal. 4 (2014) 181. Available at https://doi.org/10.5923/j.fph.20140404.0.
[10] N. Idun-acquah, G.Y. Obeng, E. Mensah, "Repetitive use of vegetable cooking oil and effects on physico-chemical properties - case of frying with redfish (Lutjanus fulgens)", Sci. Technol. 6 (2016) 8. https://doi.org/10.5923/j.scit.20160601.02.

[11] F. Soriguer, G. Rojo-Martinez, M.C.. Dobarganes, "Hypertension is related to the degradation of dietary frying oils", Am. J. Clin. Nutr. 78 (2003) 1092.

[12] A. Lapointe, C. Couillard, S. Lemieux, "Effects of dietary factors on oxidation of low-density lipoprotein particles", J. Nutr. Biochem. 17 (2006) 645.

[13] R. Kumar, S. Chandra, V. Kumar, V. Chaudhary, "Physico-chemical study of edible and composite edible oil", Int. J. Agric. Eng. 12 (2019) 129. Available at https://doi.org/10.15740/HAS/IJAE/12.1/129-135.

[14] M.A. Boda, P.N. Bhasagi, A.S. Sawade, R.A. Andodgi, "Analysis of kinematic viscosity for liquids by varying temperature", Int. J. Innov. Res. Sci. Eng. Technol. 4 (2015) 1951. Available at https://doi.org/10.15680/IJIRSET.2015.0404020.

[15] A.J. Bolton, G. Koutsianitis, "The effect of temperature on the surface tension of sap of thuja plicata heartwood", J. Wood Fiber. 12 (1980) 3.

[16] A. Ayoola, P. Anawe, M. Ojewumi, R. Amaraibi, "Comparison of the properties of palm oil and palm kernel oil biodiesel in relation to the degree of unsaturation of their oil feedstocks", Int. J. Appl. Nat. Sci. 5 (2016) 1 .

[17] A.M. Biliaed, M.A. Ahmed, M.M. Okasha, O.M. Alwakdi, A.M. Homoud, "The effects of frying on the thermal behaviour of some vegetable oils", Int. J. Agric. Res. Rev. 4 (2016) 529.

[18] C.M.C. Laranjeira, C.S.E. Ventura, S.M.C.S. Bermejo, S.P.T.A. dos Santos, M.F. da S.P. Ribeiro, D.M.G. de O.L.B. de Lima, M.O.I. Henriques, "Used food oils: physical-chemical indicators of quality degradation, FOODBALT 40 (2017) 154. https://doi.org/10.22616/foodbalt.2017.040.

[19] E. Choe, D.B. Min, "Chemistry of deep-fat frying oils", J. Food Sci. 5 (2007) 77.

[20] F. Aladedunye, R. Przybylski, "Frying performance of canola oil triacylglycerides as affected by vegetable oils minor components", J. Am. Oil Chem. Soc. 89 (2011) 1.

[21] F. Pedreschi, "Fried and Dehydrated Potato Products", Adv. Potato Chem. Technol. (2009) 319-337.

[22] M. Ghidurus, M. Turtoi, G. Boskou, P. Niculita, V. Stan, "Nutritional and health aspects related to frying", Rom. Biotechnol. Lett. 15 (2010) 5675.

[23] L.G. Chuffa, F.R. Vieira, D.A.F. Silva, D.M. Franco, Soybean Seed Oil: Nutritional Composition, Healthy Benefits and Commercial Applications", Seed Oil, Nova Science Publishers, Inc., Estadual Paulista, 2015, $1-23$.

[24] J. Mlcek, H. Druzbikova, H. Valasek, J. Sochor, T. Jurikova, M. Borkovocova, M. Baron, S. Balla, "Assessment of total polar materials in frying fats from czech restaurants", Ital. J. Food Sci. 27 (2015) 160. https://doi.org/10.14674/1120-1770/ijfs.v182.

[25] R.N. Prasada, "A study on cooking oil consumption on various health markers in rural population of Coimbatore", India, Int. J. Biomed. Res. 7 (2016) 179. Available at https://doi.org/10.7439/ijbr.

[26] E. Rukke, R.B. Sch $\tilde{\frac{1}{4}} \frac{1}{4} l$ ler, "Viscosity of a selection of edible oils and blends of oils at different temperatures", Annu. Trans. Nord. Rheol. Soc. 25 (2017) 287.

[27] R. M. Davies, "Effect of the temperature on dynamic viscosity, density and flow rate of some vegetable oils, J. Sci. Res. Eng. Technol. 1 (2016) 14.

[28] The World Gazetteer". Archived from the original on 9 February 2013, World Gazet.

[29] A.M. Chinenyeze, J.B.N. Ozibo,"Geology of parts of Gboko and Makurdi local government area", Int. J. Geol. Min. 3 (2017) 71.

[30] Makurdi - Location, Facts, Population". Encyclopedia Britannica, Retrieved on 7th Match, 2021

[31] C. A. Kogbe, A. Tokarski, D. Osijuk, D.E. Wonzy, "Geology of the Makurdi Sheet 251 in the Middle Benue Valley, Nigeria", Occas. Pub. No. 5 Dept. Geol., Ahmadu Bello Univ. Zaria, Niger. 5, 1978.

[32] I.O. Agbede, P. Smart, "Geotechnical Properties of Makurdi Shale and Effects on Foundations", Niger. J. Technol. 26 (2007) 63.

[33] K.F. Aov, I. Okon, C. G.Njoku, K.A. Thaddeus, S.A. Iorkua, T. Olorundami, I.J. Lekam, "Spatial Analysis of Crime Incidents in Makurdi Metropolis, Benue State, Nigeria”, in Proceedings of 58th Assoc. Niger. Geogr. Annu. Conf., Nasarawa State Univ. Keffi, Nasarawa State , Niger., 
2017.

[34] S.N. Sahasrabudhe, V. Rodriguez-martinez, M.O. Meara, B.E. Farkas, S.N. Sahasrabudhe, V. Rodriguez-martinez, M.O. Meara, "Density, viscosity, and surface tension of five vegetable oils at elevated temperatures: measurement and modeling", Int. J. Food Prop. 20 (2017) 1965. https://doi.org/10.1080/10942912.2017.1360905.

[35] B.E. Laboratories, Brookfield Dial Viscometer Operation Instructions,
Brookfield engineering laboratories, inc. 11, Commerce Boulevard, Middleboro, MA 02346-1031 USA.

[36] M.S. Sarjadi, T.C. Ling, M.S. Khan, "Analysis and comparison of olive cooking oil and palm cooking oil properties as biodiesel feedstock", J. Phys. Conf. Ser. 1358 (2019) 1. Available at https://doi.org/10.1088/17426596/1358/1/012007. 